\title{
Bone Damage Induced by Different Cutting Instruments - An In Vitro Study
}

\author{
Umberto ROMEO $^{1}$ \\ Alessandro DEL VECCHIO ${ }^{1}$ \\ Gaspare PALAIA $^{1}$ \\ Gianluca TENORE ${ }^{1}$ \\ Paolo VISCA ${ }^{2}$ \\ Claudia MAGGIORE 3
}

\author{
${ }^{1}$ Department of Odontostomatological Science, Sapienza University of Rome, Viale Regina Elena, Rome, Italy \\ ${ }^{2}$ Department of Cytology and Cellular Diagnostics, Regina Elena Institute, Rome, Italy \\ ${ }^{3}$ University of L'Aquila, L'Aquila, Italy
}

\begin{abstract}
The aim of this study was to compare the peripheral bone damage induced by different cutting systems. Four devices were tested: Er:YAG laser $(2.94 \mu \mathrm{m})$, Piezosurgery, high-speed drill and low-speed drill. Forty-five bone sections, divided into 9 groups according to different parameters, were taken from pig mandibles within $1 \mathrm{~h}$ post mortem. Specimens were fixed in 10\% buffered formalin, decalcified and cut in thin sections. Four different parameters were analyzed: cut precision, depth of incision, peripheral carbonization and presence of bone fragments. For statistical analysis, the Kruskal-Wallis test was applied to assess equality of sample medians among groups. All sections obtained with the Er:YAG laser showed poor peripheral carbonization. The edges of the incisions were always well-shaped and regular, no melting was observed. Piezosurgery specimens revealed superficial incisions without thermal damage but with irregular edges. The sections obtained by traditional drilling showed poor peripheral carbonization, especially if obtained at lower speed. There was statistically significant differences $(\mathrm{p}<0.01)$ among the cutting systems for all analyzed parameters. Er:YAG laser, gave poor peripheral carbonization, and may be considered an effective method in oral bone biopsies and permits to obtain clear and readable tissue specimens.
\end{abstract}

Key Words: laser, piezosurgery, bone biopsy, peripheral damage.

\section{INTRODUCTION}

Biopsy is a histological procedure made to analyze and to confirm a clinical diagnosis. Incisional biopsy removes one or more pathological samples to start an adequate therapy after observing the histopathological response. Excisional biopsy is the complete removal of the lesion and it is both a diagnostic and a therapeutic procedure. In a biopsy, safety of edges of the tissue specimen is essential to prevent mistakes, especially in potentially dysplastic or neoplastic lesions (1).

Several cutting instruments can be used in bone surgery, namely drills, piezosurgery and lasers. Drillers are the most common bone cutting instruments and until few years ago, they were the sole devices used to cut bone tissue. In recent years, Piezosurgery and erbium lasers were introduced in bone surgery.

Piezoelectric bone surgery, also simply known as piezosurgery, is a new technique for osteotomy and osteoplasty created by Tommaso Vercellotti utilizing an innovative ultrasonic surgical apparatus, known as the Mectron piezosurgery device (2). Piezosurgery was developed in response to the need to reach major levels of precision and intraoperative safety in bone surgery, as compared to that available by the traditional manual and motorized bone cutting instruments. It is claimed as ideal to perform osteotomies in thin and fragile bones. The application of ultrasound is precise and easily handled, and the microvibrations allow a selective cut of only mineralized structures, creating minimal damage to

Correspondence: Umberto Romeo, Department of Odontostomatological Science, Sapienza University of Rome, Viale Regina Elena 287/A, 00161 Rome, Italy. Tel: +39-06-4997-6639. Fax:+39-06-4423-0811. e-mail: umberto.romeo@uniroma1.it 
adjacent soft tissues (3). A previous study (4) has found no differences between Piezosurgery and conventional instruments in some applications, as maxillary sinus augmentation, and the piezoelectric device has also been shown very useful in surgical procedures requiring a particular caution, such as mental nerve transposition (5). In contrast to the macrovibration and extreme noise produced by drilling procedures, Piezosurgery produces microvibration and little noise, which minimize patient's psychological stress and fear during osteotomy under local anesthesia (6).

The Er:YAG laser was approved by the US Food and Drug Administration in 1997 for the treatment of oral hard tissues and has shown several potential applications in Periodontology, Oral Surgery, Restorative Dentistry and Implantology. It has an infrared emission $(2.94 \mu \mathrm{m}$ wavelength), is entirely absorbed by water, and works on all hydrated oral tissues (bone, tooth, oral mucosa). The high biological interaction with hard tissues depends on a particular thermo-induced mechanical effect creating sharp and well circumscribed superficial incisions. Er:YAG laser ablates tissues effectively without burning, melting, or altering the calcium-to-phosphorus $(\mathrm{Ca} / \mathrm{P})$ ratio of the irradiated bone $(7,8)$. This bone ablation technique, using short pulses and water spray, has been shown to produce good clinical results in bone surgery procedures without any impairment to wound healing (9). However, thermal damage at the margins of the ostectomies has been reported, if cooling is not adequate (10). Moreover, the longer time required to perform osteotomy in impacted tooth surgery limits routine clinical application of Er:YAG laser (9), while the need of carefully handling the laser beam position and its angulation and the lack of depth control (11), adjustable with sensor controlled systems, limit the use of Er:YAG laser devices to regions where a safe and fixed guidance of the laser beam is feasible.

The aim of the present study was to compare, by histological examination, the structure of bone sections performed with Er:YAG laser, high-speed and low-speed drills and Piezosurgery in order to evaluate which device performs bone biopsies safely and without instrumental artifacts.

\section{MATERIAL AND METHODS}

The following instruments were evaluated in this study: an Er:YAG laser (2.94 $\mu \mathrm{m}$ Delight, Sweden
Martina, Italy) device set at 2 parameter settings; a piezoelectric device (Mectron, Vicenza Italy) set at 2 parameter settings; a high-speed handpiece (Bien Air, Dental SA, Bienne, Switzerland) using Lindemann burs (Komet, Lemgo, Germany) and round diamond burs (Diatech Dental AG, Heerbrugg, Switzerland); and a low-speed handpiece (W\&H Dentalwerk Burmoos $\mathrm{GmbH}$, Austria) using round stainless steel burs (Hager \& Meisinger GmbH, Neuss, Germany).

The study was performed on pig cadaver bone, which was chosen due to its physiological structure similar to that of human bone. In two fresh pig mandibles, 45 bone sections were practiced, divided into 9 groups of 5 sections each, as follows:

Er:YAG laser groups (A1 and A2): The specimens in the A1 group were prepared with laser settings of 3 $\mathrm{W}, 30 \mathrm{~Hz}, 100 \mathrm{~mJ}$ and $35 \mathrm{~J} / \mathrm{cm}^{2}$, and in the $\mathrm{A} 2$ group the laser settings were $6 \mathrm{~W}, 30 \mathrm{~Hz}, 200 \mathrm{~mJ}$ and $70 \mathrm{~J} / \mathrm{cm}^{2}$. In both groups, fiber tip with diameter of $600 \mu \mathrm{m}$ was used in noncontact mode and with water spray cooling.

Piezosurgery groups: The B1, B2 and B3 groups included specimens cut with the piezoelectric device at quality 1, 2 and 3 parameters, respectively. An OT7 tip was used with modulated functional working frequency of $24-29 \mathrm{KHz}$, gentle scratching movements, and very little pressure.

High-speed handpiece groups: The specimens in the $\mathrm{C} 1$ and $\mathrm{C} 2$ groups were prepared with a high-speed handpiece (400,000 rpm) using a Lindemann bur (ISO diameter 016) and a diamond round bur (ISO diameter 016), respectively. Bone cuts were always performed under water cooling and using an intermittent pressure on bone in order to cause the least thermal damages.

Low-speed handpiece group: The specimens in the D1 and D2 groups were prepared with a low-speed handpiece set at 20,000 and 40,000 rpm, respectively, using a stainless steel round bur (ISO diameter 018) in both cases. Bone cuts were always performed under water cooling and using an intermittent pressure on bone in order to cause the least thermal damages.

All bone sections were prepared by the same oral surgeon, while a second operator placed the specimens in sterile test tubes labeled with the alpha-numeric code, containing a $10 \%$ buffered formalin solution. The bone sections were immersed in a decalcifying solution (New Decalc, Medite GmbH, Burgdorf, Switzerland) for $72 \mathrm{~h}$. Samples were taken from cortical incisions, dehydrated, cleared and embedded in paraffin. The inclusions were 
cut with a rotary microtome into $5-\mu \mathrm{m}$-thick sections, which were stained with hematoxylin and eosin, and examined with an optical microscope (Primo Star, Zeiss, Oberkochen, Germany) at $\times 25$ and $\times 40$ magnifications, by 2 pathologists to avoid any personal bias. The examiners analyzed cut precision (sharpness), depth of incision (depth), peripheral thermal damages (carbonization) and presence of bone debris (bone fragments), which are essential parameters to assess the reliability of a biological sample, and attributed scores from 0 (low grade) to 3 (high grade). For each group, the scores were averaged to obtain a single value per group. The ratings of evaluations are summarized in Figure 1. All samples were treated at the Regina Elena Institute of Rome, Italy.

For statistical analysis, the non-parametric Kruskal-Wallis test was applied to test equality of sample medians among groups (Epi Info software 3.4.3; Centers for Disease Control and Prevention, Atlanta, GA, USA). Then all parameters (sharpness, depth, carbonization and

\section{SHARPNESS}

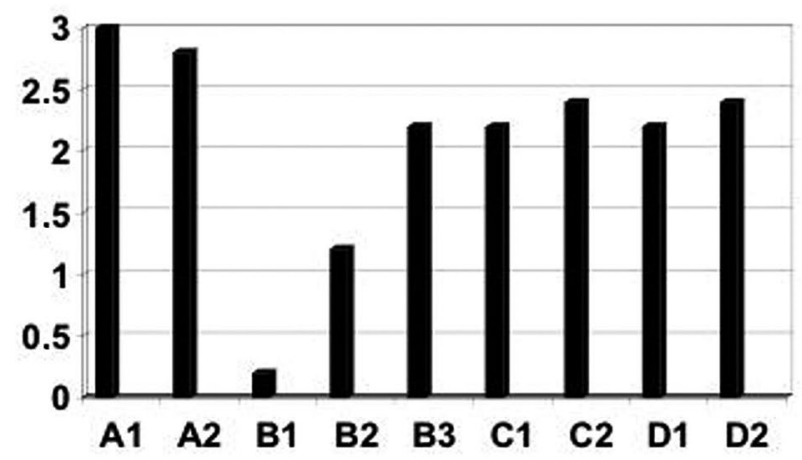

CARBONIZATION

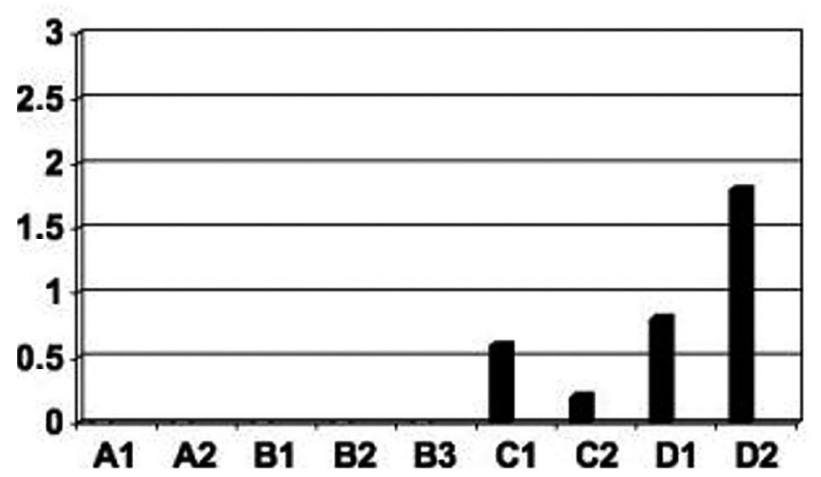

bone fragments) were analyzed separately in a linear regression model, examining laser groups in comparison to the other groups.

\section{RESULTS}

\section{Quantitative Analysis}

There were statistically significant differences $(p<0.01)$ among the groups for all the analyzed parameters (sharpness, depth, carbonization and bone fragments).

The statistical analysis showed that according to the adopted criteria in the linear regression, Sharpness was inversely proportional in B1 and B2. Bone fragments were inverse to sharpness $\left(r^{2}=0.80\right)$. Bone fragments were directly related to all the groups except for the A groups $\left(\mathrm{r}^{2}=0.86\right)$. Carbonization was directly related to $\mathrm{D} 1$ and D2 $\left(\mathrm{r}^{2}=0.60\right)$. Moreover depth was in inverse

\section{DEPTH}

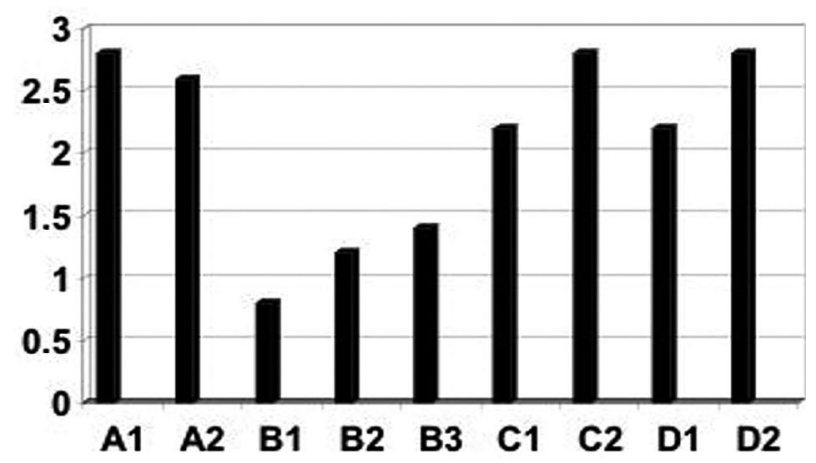

BONE FRAGMENTS

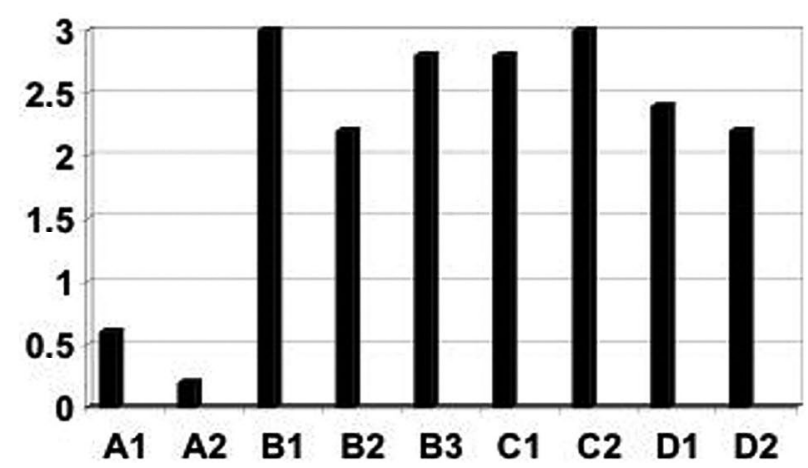

Figure 1. Scores (0-3) attributed to each group for the parameters sharpness, depth, carbonization and bone fragments. 
proportion to B groups $\left(\mathrm{r}^{2}=0.68\right)$.

\section{Qualitative Analysis}

A1 and A2 groups (Er:YAG laser). Generally, Er:YAG laser gave excellent results for all parameters. Clear sharp edges, good depth of incision, low melting and carbonization were observed almost in all the analyzed samples. The extent of thermal damage was always no more than a few microns as it is visible in the reported sample of A1 group (Fig. 2). In A2 group, in which doubled parameters were applied, a very low thermal artifact was present and it is clearly visible the sharp cut edge and the poor thermal alterations of the intertrabecular connective tissue; even the osteocytes close to the incision are lacking alterations.

B1, B2 and B3 groups (Piezosurgery). Piezosurgery incisions showed superficial incisions without thermal signs but with irregular margins. The absence of thermal damage is obvious since the own cutting properties of the device. However, in all the samples cut with the piezoelectric device the histological sharpness of the incision was not generally satisfactory (Fig. 3).

C1 and C2 groups (high-speed handpiece): The Lindemann bur cut (group C1), was generally irregular in depth and shape. The edges were full of bone fragments and a low grade thermal damage was clearly visible (Fig. 4). The diamond bur (group C2), created clear and deep edges, very high grade of bone fragments but no signs

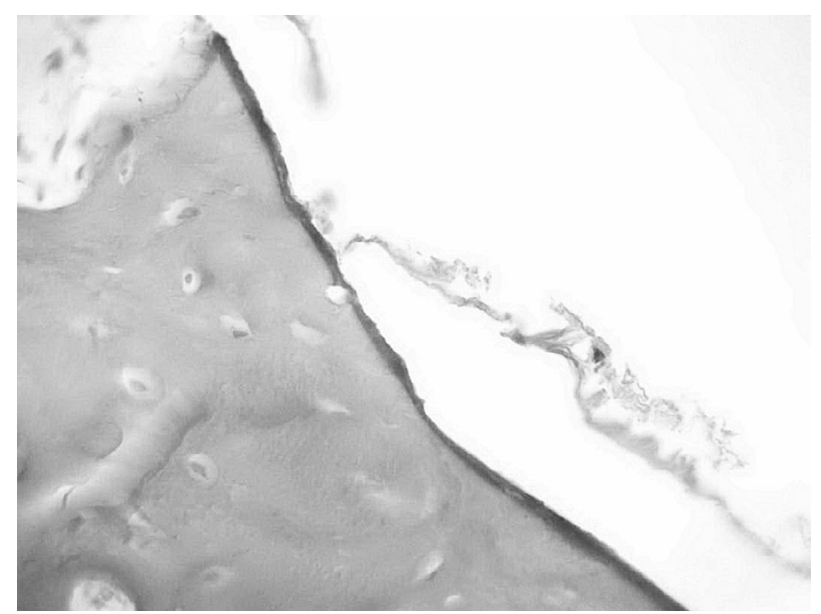

Figure 2. Image of a specimen of A1 group (Er:YAG laser, $30 \mathrm{~Hz}$, $\left.100 \mathrm{~mJ}, 35 \mathrm{~J} / \mathrm{cm}^{2}\right)$ showing a very precise cut without thermal damage $(\times 25$ magnification $)$. of thermal damage (Fig. 5).

D1 and D2 groups (low-speed handpiece): At 20,000 rpm (group D1), with steel burs, deep and clear incisions were generally observed. The margins were fragmented and low grade of thermal signs on the cortical surface were often present (Fig. 6). In the specimens obtained at 40,000 rpm (group D2), the cut was generally sharp and deep. The cortical surface showed signs of thermal damage and many bone fragments were generally present.

\section{DISCUSSION}

Biopsy is a surgical diagnostic procedure performed to establish a clear diagnosis of a lesion to confirm or not the clinical diagnostic hypothesis. Performing a biopsy it is fundamental to keep cut margins safe and readable to permit the pathologist a clear vision about the possible marginal infiltration and malignant transformation of dysplastic or neoplastic lesions. In Oral Pathology, it is fundamental for a clear histological diagnosis that the whole biopsied specimen was intact and clearly readable, especially in suspected neoplastic or dysplastic lesions. The peripheral cellular layers of specimen are extremely important for the evaluation of the infiltrating potential of the lesion. Therefore, any surgical device that creates thermal or mechanical damage on surrounding tissues during a biopsy is not safe to perform this procedure (1).

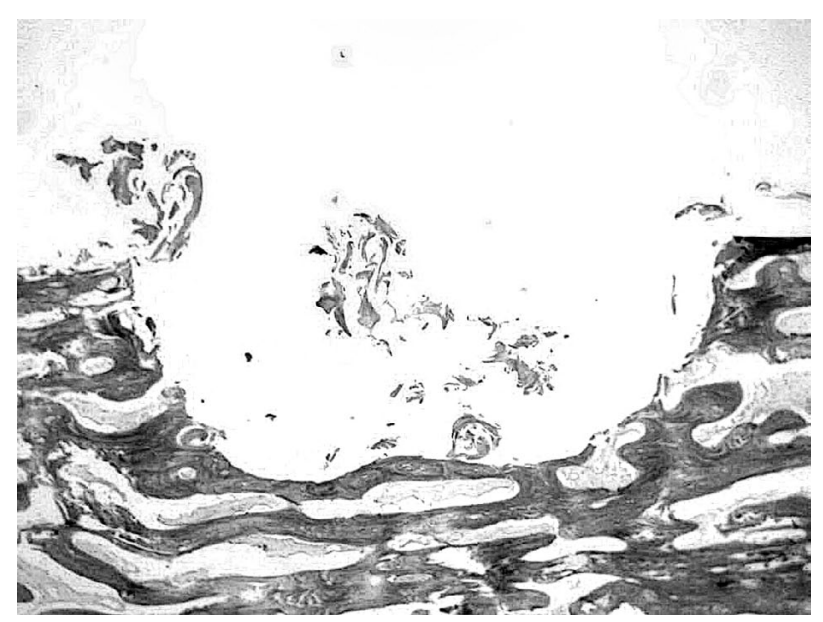

Figure 3. Image of a specimen of B2 group (Piezosurgery, Quality 2) showing a very superficial incision, irregular edges, but no significant thermal damage $(\times 25$ magnification $)$. 
Oral osteotomies can be achieved by several methods, most frequently by low- and high-speed bur drilling. For other specific procedures, chisels and bone saws are used. Recently, high-energy lasers have been introduced. Lasers have been used in medical applications since the early sixties. Some of the medical specialities in which the lasers are used include Otolaryngology, Orthopedics, Dermatology, Ophthalmology, Neurology, Cardiology, Gastroenterology, Urology, and Nephrology (10).

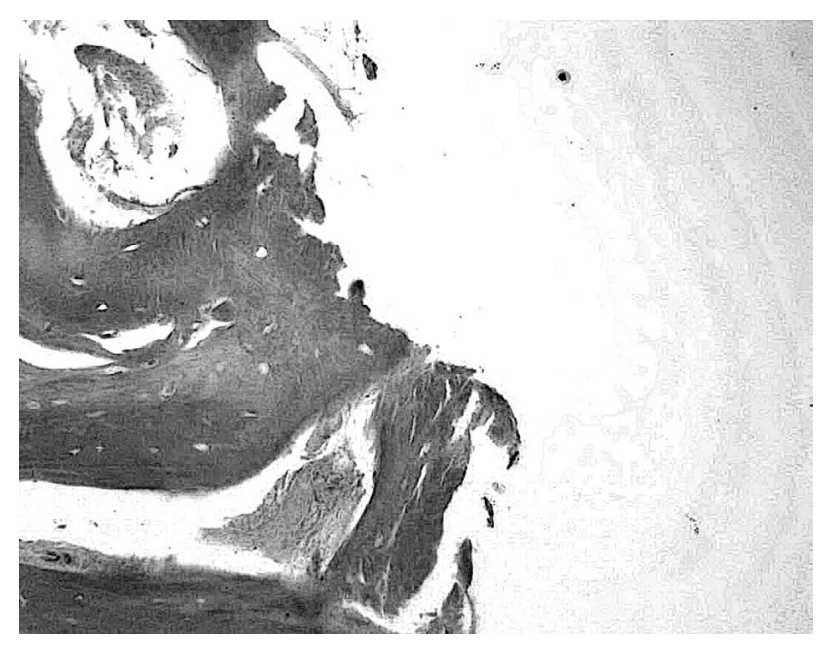

Figure 4. Image of a specimen of $\mathrm{C} 1$ group (Lindemann bur) showing irregular deep cut with irregular margins $(\times 25$ magnification $)$.

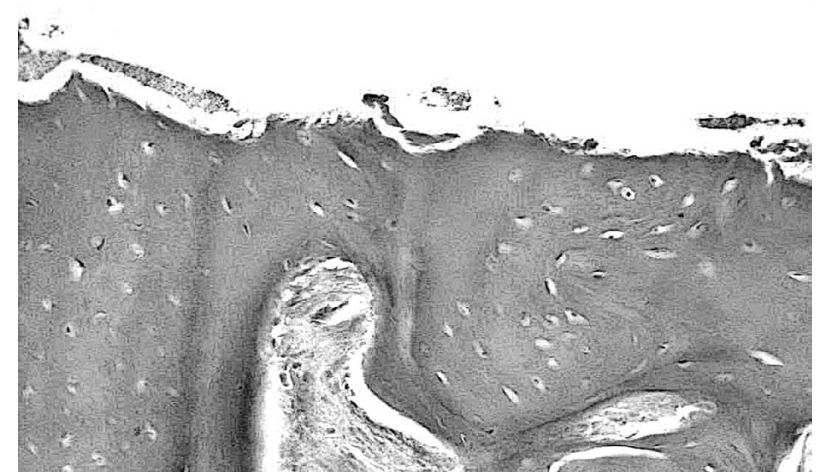

Figure 5. Image of a specimen of $\mathrm{C} 2$ group (diamond bur) showing clear and deep cut margins. Many bone fragments and no signs of thermal damage $(\times 25$ magnification $)$.
The Er:YAG laser has an infrared emission that is totally absorbed by water and works on all hydrated oral tissues. The high biological interaction with hard tissues depends by a particular thermo-induced mechanical effect. The Er:YAG radiation is absorbed by water that explodes and evaporates, creating sharp and well circumscribed superficial incisions; this laser can be used in pulsed or super pulsed mode, with or without air/water cooling, with the possibility of changing the power frequency and energy settings. Optic fibers of different diameters, from large size to small, about 200 $\mu \mathrm{m}$ provide to light transmission. The Er:YAG laser can be successfully applied in many operative fields, as Restorative Dentistry (tooth decay treatment, enamel etching, etc.) (12-14), Endodontics (root canal disinfection) (15), Periodontology (disinfection of periodontal defects, periodontal surgery) (16) and oral soft tissue surgery (17). The advantages of the employment of the Er:YAG laser in oral osteotomies are the high cut capability, the sharpness of cut edges and the minimal thermal damage of surrounding tissues thanks to the water microexplosion ablation mechanism (7-9). However, the laser procedure is longer than conventional bur technique (8) and some patients objected to the sound and smell of the laser surgical procedure, finding it unpleasant (9).

In the present study, the Er:YAG laser showed the highest level of bone cut precision at various depths, especially if compared with traditional bur methods, and

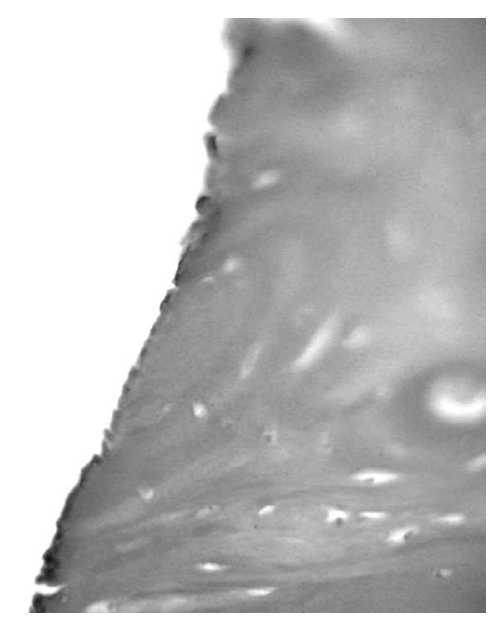

Figure 6. Image of a specimen of D1 group (20,000 rpm stainless steel bur) showing deep and precise cut, with irregular edges and no significant thermal damage on the cut area $(\times 25$ magnification $)$. 
the total lack of bone fragments that is fundamental for a good healing. In fact, all the examined samples were safe with minimal thermal damage always limited to a few micrometers close to the incision. These results confirm those obtained by other authors $(18,19)$. In fact in a recent study of Sasaki et al. (19), the irradiated site presented a groove of approximately $630 \mu \mathrm{m}$ width and $240 \mu \mathrm{m}$ depth with precise boundaries and even safe osteocytes nuclei could be observed approximately $30 \mu \mathrm{m}$ apart from the irradiated surface. Also, the thin laser-altered layer presented 2 distinct layers: a superficial layer, where numerous micro-cracks gave a porous appearance and a dark, less affected deep layer, which had less micro-cracks. In fact, the deeper layer, which receives less energy, suffers mainly from the effects of energy accumulation. In the directly irradiated surface, which receives more energy, cracks and micro-fractures are formed after micro-explosions, leading to mechanical tissue removal, and the consequent loss of $\mathrm{Ca}$ and $\mathrm{P}$ from the irradiated bone surface (19).

Lewandrowski et al. (20) reported that the healing rate, following Er:YAG laser irradiation, may be similar or even faster than the one of bur drilling. Besides, the lack of smear layer and the typical irregular pattern presented by the irradiated tissue may potentially enhance the adhesion of blood elements at the start of the healing process.

According to our experience, Piezosurgery presented a low grade cut precision. Cut edges showed poor histological sharpness with irregular cut lines. However, in all samples, no thermal damage was present. Piezosurgery is largely the less traumatic device in our series, however it presents poor depth of incision and several bone debris in the surgical cut margin. The Piezosurgery creates an effective osteotomy, producing less vibration and noise because it uses microvibration, in contrast to the macrovibration and extreme noise that occur with a surgical saw or bur as seen by Sohn et al. (6).

At last, both high- and low-speed rotating instruments presented as the main feature, a large number of bone fragments in almost every sample. In particular, the low-speed handpiece at lower speed showed poor results in all the tested parameters.

Traditional rotating instruments gave generally good results, however their action is always more traumatic than laser and Piezosurgery; moreover their action is strictly related to the surgeon's capability, giving less predictable results over the treated surfaces. This is in accordance with the results of Sasaki (19), who showed that bur-treated bone also exhibited a groove of approximately $730 \mu \mathrm{m}$ width and $290 \mu \mathrm{m}$ depth. The surface of the groove was covered with a thin smear layer with a regular border and, under transmission electron microscopy, the bur-drilled surface showed cracking and roughness that was not observed under light microscopy.

Both the statistical and histological analyses revealed that the Er:YAG laser is a very helpful device in bone oral surgery as largely shown in literature $(7,8,10,11,19,20)$; in fact, its particular interaction with biological tissues containing water and hydroxyapatite allows extremely precise bone cuts. Moreover, the air/ water cooling prevents the thermal increase minimizing the thermal damage in peripheral cut margins.

The duration of bone cutting procedures was not an object of this study. The time needed to complete a laser osteotomy is a clear limit for the application of this device in clinical practice (8). Nevertheless, the lower speed of execution of laser incision is largely balanced by the high quality of results obtained with this device. In contrast, laser requires a long learning period to avoid the possibility of causing tissue damages. It is reasonable to suggest to inexperienced operators to start with lower parameters, increasing them during the procedure if the requested effect is not achieved.

In conclusion, Er:YAG laser gives clear advantages to surgeons in the treatment of maxillary bone lesions. Standardized depth, sharp edges and no bone fragments are the cornerstones of this technique. All these benefits are strictly related to the parameters applied, so it is necessary to have an adequate knowledge of both the device and the biological tissues response in order to operate a safe surgery.

\section{RESUMO}

O objetivo deste estudo foi comparar o dano ósseo periférico produzido por diversos sistemas de corte. Foram avaliados 4 dispositivos: laser Er:YAG (2,94 mm), Piezo-cirurgia, broca em alta rotação e broca em baixa rotação. Para isto, foram utilizadas 45 seções ósseas retiradas de mandíbulas de suínos, até $1 \mathrm{~h}$ post-mortem, divididas em 9 grupos de acordo com diversos parâmetros. As amostras foram fixadas em formalina a 10\% tamponada, descalcificadas e cortadas em lâminas finas. Foram analisados 4 parâmetros diferentes: a precisão do corte, a profundidade da incisão, a carbonização periférica e presença de fragmentos ósseos. A análise estatística empregou o teste de Kruskal-Wallis para avaliar a similaridade das medianas entre os grupos. Todas as seções feitas com o laser Er:YAG exibiram pouca carbonização. As margens das incisões foram todas bem acabadas 
e regulares, sem apresentar pontos de fusão. As amostras obtidas por piezo-cirurgia apresentaram incisões superficiais sem danos térmicos, mas com margens irregulares. As seções obtidas pelas brocas convencionais apresentaram pouca carbonização marginal, particularmente as feitas em baixa rotação. Foram observadas diferenças estatisticamente significantes $(p<0,01)$ entre todos os sistemas de corte para cada um dos parâmetros analisados. O laser Er:YAG apresentou pouca carbonização e pode ser considerado como um método eficaz para biópsias de ossos bucais, produzindo amostras de tecido limpas e fáceis de analisar.

\section{REFERENCES}

1. Romeo U, Del Vecchio A, Ripari F, Palaia G, Chiappafreddo C, Tenore G, et al.. Effects of different laser devices on oral soft tissues: in vitro experience. J Oral Laser Appl 2007;7:155-159.

2. Vercellotti T. Technological characteristics and clinical indications of piezoelectric bone surgery. Minerva Stomatol 2004;53:207-214.

3. Gonzalez-Garcia A, Diniz-Freitas M, Somoza-Martin M, GarciaGarcia A. Piezoelectric and conventional osteotomy in alveolar distraction osteogenesis in a series of 17 patients. Int J Oral Maxillofac Implants 2008;23:891-896.

4. Barone A, Santini S, Marconcini S, Giacomelli L, Gherlone E, Covani U. Osteotomy and membrane elevation during the maxillary sinus augmentation procedure. A comparative study: piezoelectric device $v s$ conventional rotative instruments. Clin Oral Implants Res 2008;19:511-515.

5. Sakkas N, Otten JE, Gutwald R, Schmelzeisen R. Transposition of the mental nerve by piezosurgery followed by postoperative neurosensory control: a case report. Br J Oral Maxillofac Surg 2008; 46:270-271.

6. Sohn DS, Ahn MR, Lee WH, Yeo DS, Lim SY. Piezoelectric osteotomy for intraoral harvesting of bone blocks. Int J Periodontics Restorative Dent 2007;27:127-131.

7. Kimura Y, Yu DG, Fujita A, Yamashita A, Murakami Y, Matsumoto K. Effects of erbium, chromium: YSGG laser irradiation on canine mandibular bone. J Periodontol 2001;72:1178-1182.

8. Papadaki M, Doukas A, Farinelli WA, Kaban L, Troulis M. Vertical ramus osteotomy with Er:YAG laser: a feasibility study. Int J Oral Maxillofac Surg 2007;36:1193-1197.

9. Stubinger S, von Rechenberg B, Zeilhofer HF, Sader R, Landes C. Er:YAG laser osteotomy for removal of impacted teeth: clinical comparison of two techniques. Lasers Surg Med 2007;39:583-588.
10. de Mello ED, Pagnoncelli RM, Munin E, Filho MS, de Mello GP, Arisawa EA, et al.. Comparative histological analysis of bone healing of standardized bone defects performed with the Er:YAG laser and steel burs. Lasers Med Sci 2008;23:253-260.

11. Stubinger S, Nuss K, Landes C, von Rechenberg B, Sader R. Harvesting of intraoral autogenous block grafts from the chin and ramus region: preliminary results with a variable square pulse Er:YAG laser. Lasers Surg Med 2008;40:312-318.

12. Chimello DT, Serra MC, Rodrigues AL Jr, Pecora JD, Corona SA. Influence of cavity preparation with Er:YAG Laser on enamel adjacent to restorations submitted to cariogenic challenge in situ: a polarized light microscopic analysis. Lasers Surg Med 2008;40:634-643.

13. Esteves-Oliveira M, Zezell DM, Apel C, Turbino ML, Aranha AC, Eduardo $\mathrm{C}$ de $\mathrm{P}$, et al.. Bond strength of self-etching primer to bur cut, Er,Cr:YSGG, and Er:YAG lased dental surfaces. Photomed Laser Surg 2007;25:373-380.

14. Delmè KI, De Moor RJ. Scanning electron microscopic evaluation of enamel and dentin surfaces after Er:YAG laser preparation and laser conditioning. Photomed Laser Surg 2007;25:393-401.

15. Noiri Y, Katsumoto T, Azakami H, Ebisu S. Effects of Er:YAG laser irradiation on biofilm-forming bacteria associated with endodontic pathogens in vitro. J Endod 2008;34:826-829.

16. Lopes BM, Marcantonio RA, Thompson GM, Neves LH, Theodoro LH. Short-term clinical and immunologic effects of scaling and root planing with Er:YAG laser in chronic periodontitis. J Periodontol 2008;79:1158-1167.

17. Rosa DS, Aranha AC, Eduardo C de P, Aoki A. Esthetic treatment of gingival melanin hyperpigmentation with Er:YAG laser: shortterm clinical observations and patient follow-up. J Periodontol 2007;78:2018-2025.

18. Gonzalez C, van de Merwe Wp, Smith M, Reinich L. Comparison of the erbium-yttrium alumunium garnet and carbon dioxide lasers for in vitro bone and cartilage ablation. Laryngoscope 1990;100:14-17.

19. Sasaki KM, Aoki A, Ichinose S, Yoshino T, Yamada S, Ishikawa I. Scanning electron microscopy and Fourier transformed infrared spectroscopy analysis of bone removal using Er:YAG and CO2 lasers. J Periodontol 2002;73:643-652.

20. Lewandrowski KU, Lorente C, Schomacker KT, Flotte TJ, Wilkes JW, Deutsch TF. Use of the Er:YAG laser for improved plating in maxillofacial surgery: comparison of bone healing in laser and drill osteotomies. Lasers Surg Med 1996;19:40-45.

Accepted February 13, 2009 